\title{
The Influence of Human Values on Holiday Destination Choice in Australia and Brazil
}

\author{
Claudio Vaz Torres* \\ E-mail address: claudpsius@aol.com \\ Universidade de Brasília - UnB \\ Brasília, DF, Brazil \\ Amalia Raquel Pérez-Nebra \\ E-mail address: amalia@unb.br \\ Universidade de Brasília - UnB \\ Brasília, DF, Brazil
}

\begin{abstract}
Allen and Ng (1999a) proposed a conceptual framework of how consumers' choice of services may be influenced by the human values that they endorse. The aim of this study is to observe which implications cultural differences had on holiday destination choice. The sample consisted of 793 participants (52\% Brazilians, 48\% Australians; 51\% Male; average age $=25 \mathrm{y}$; Education 52\% High School), who answered a questionnaire containing: the vertical-horizontal individualism-collectivism Values Scale, the Meaning and Judgment Scale, a Holiday Destination Measure, a Consumption Behavior Measure, and demographics page. The main effect of the country on cultural patterns between Brazil and Australia was observed. The individualist Australians preferred a piecemeal judgment and placed more importance on tangible attributes. Brazilians, who scored higher on collectivism, used affective judgment more. These and other results are discussed in terms of the validity of the model for individuals who endorse cultural values other than individualism.
\end{abstract}

Key words: consumer behavior; destination choice; human values; product judgment and meaning; two-route model.

Copyright (C) 2007 Brazilian Administration Review. All rights reserved, including rights for translation. Parts of this work may be quoted without prior knowledge on the condition that the source is identified.

*Corresponding author: Cláudio Vaz Torres

Universidade de Brasília, Instituto de Psicologia, Departamento de Psicologia Social e do Trabalho, Campus Universitário Darcy Ribeiro, ICC Sul, Sala A1 052ª , Asa Norte, 70910-900, Brasília/DF, Brazil. 


\section{INTRODUCTION}

The literature on consumer behavior has been describing consumption of service, such as those related to holiday services, or buying process like destination choice (Sönmez \& Sirakaya, 2002). Studies about the practices of cross-cultural consumers must take into consideration the culture variable, and the national culture of a society can be examined by measuring the cultural dimensions of a country. Although there is a broad discussion about the concept of culture, for Triandis (1994), the analysis of subjective culture allows us to understand people's perceptions, make social categorizations, formulate beliefs, and value specific aspects of the social ambience around them. The present study intends to examine this element, subjective culture, which has already been found to correlate with consumer expectations and satisfaction elsewhere (Kahle, 1996). In the investigation of the subjective aspects of culture, this study has the general objective of observing which implications cultural differences, as they relate to individualism and collectivism, have on consumer behavior. Thus, it is important to clarify how culture is being understood in this study and its relationship with consumer behavior in tourism.

\section{CULTURE AND CONSUMERS}

Heller (1987) suggests that national and ethnic cultures are distinguished by their regulation degree of behavior, attitudes, and values, the consistency and clarity of regulation and tolerance of other cultures. Moreover, we must note that culture is not restricted to our beliefs or values (Ferdman, 1992). The ways that we 'make sense of experiences' regulates what we expect and what we consider to be 'acceptable' from other people. There appears to be an agreement in the field that culture entails different elements, which give people a predisposition to act in ways considered to be most appropriate in their own reality.

Hofstede (1980) provided a more succinct definition of culture. He considered that culture is a kind of "program" that controls behavior. Hofstede $(1980,1991)$ studied data from 53 countries, and identified four dimensions of cultural variations through studying over 117,000 questionnaires completed by respondents at different time periods and matching the responses by occupation, age and sex. His research showed that people would have different intentions, give different attributions, and behave differently due to their cultural group.

Of main interest here is the finding, by Hofstede (1991), that culture can be used as a predictive variable. It has been used for this purpose in several research programs, with different objects, not only in Psychology (for a comprehensive review, see Smith, Bond, \& Kagitçibasi, 2006), but also in Marketing (e.g., Kahle, 1996), Advertising (e.g., Mooij, 2004), and Consumer Research in general (e.g., Allen, Ng, \& Wilson, 2002). With the rapid increase in information exchange between countries, people increasingly give greater importance to their own cultural identity, resulting in a divergence in their consumption behavior, media usage, and even taste (Cervellon \& Dubé, 2002; Smith \& Bond, 1999). For Mooij (2004), Hofstede's dimensions have led to many useful explanations of crosscultural differences in consumer behavior and, what is most important, his country scores obtained in the 1970s are still valid for comparative cross-cultural studies of consumer behavior some 30 years later. This position is agreed on by several other scholars, such as Shavitt, Lalwani, Zhang, and Torelli (2006), who have argued for the importance of the vertical-horizontal manifestations of Hofstede's individualism-collectivism cultural dimension in cross-cultural consumer studies.

The four dimensions identified by Hofstede (1980) are masculinity-femininity, uncertainty avoidance, power distance, and individualism-collectivism. Extensive discussions and reviews of the latter dimension are presented by Smith and Bond (1999), and Triandis (1994). Individualismcollectivism reflects the extent to which people emphasize personal or group goals. Hofstede (1983) 
observed that members of individualistic cultures are focused on "doing their own thing," while members of collectivist cultures give preference to in-group over individual goals.

Some scholars (e.g., Triandis, 1994) suggest that the individualism-collectivism (IC) dimension is essential for the analysis of a culture, since a large number of studies (e.g., Ashmos \& McDaniel, 1996; Campbell, Bommer, \& Yeo, 1993; Smith \& Bond, 1999; Triandis, McCusker, \& Hui, 1990) have demonstrated the influence of this dimension on the behavior of the members of a social group. Despite this interest in the IC dimension, Singelis, Triandis, Bhawuk and Gelfand (1995) suggested that the individualism and collectivism constructs are too broad for an accurate measurement. Thus, Singelis et al. (1995) proposed two new constructs, the vertical and horizontal variations of individualism-collectivism, which would be more useful for empirical research.

The concept of verticality recognizes that inequalities between people require a certain amount of conformity according with hierarchy, while horizontalness increases the sense that individuals should be free from the influences of others. When we analyze the different forms of IC from this perspective, we come up with a two-by-two matrix, describing four types of cultural patterns: verticalindividualism, horizontal-individualism, vertical-collectivism, and horizontal-collectivism. Shavitt et al. (2006), presented evidence that highlights the value of the vertical/horizontal distinction of IC as a predictor of consumer behavior.

Because groups between societies can be differentiated in terms of a large number of criteria, choosing which group should be studied can be a difficult task. There is some scientific evidence (e.g., Triandis \& Gelfand, 1998; Triandis, Chen, \& Chan, 1998) demonstrating the importance of measuring which of these four cultural patterns is more valued by a social group, and how these cultural patterns have an impact on other social behaviors. There is evidence that the scale of Singelis et al. (1995) may be limited because it represents an imposed ethic in Brazil, capturing the four cultural patterns with some limitations (Nogueira, Torres, Guimarães, \& Lucas, 2002; Nogueira, 2001; Torres, 1999). Therefore, in this study we have chosen to investigate these cultural patterns and their relationship with consumer behavior in two distinct social groups, Australia and Brazil, which have differences in relation to their position on the IC continuum.

We can assume (Torres \& Dessen, 2002) that Brazilian culture is an example of a culture where collectivist values are preferred. Traditionally, Brazil has been categorized as a collectivist culture (e.g., Hofstede, 1980; Torres, 1999; Van Horn \& Marques, 1999). As members of a collectivist society (Hofstede, 1980), Brazilians see themselves as belonging to an in-group. Furthermore, it has been suggested that they recognize and accept inequality and differences in status (Pearson \& Stephan, 1998). On the other hand, individualism is a cultural pattern in which an autonomous self is postulated. Singelis et al. (1995) suggest that Australian culture would be good example of a place where the preferred cultural pattern is individualist.

\section{Consumer Behavior in Tourism}

The field of consumer behavior in tourism has made a great deal of progress in recent years, enhancing the exploration of topics investigated, such as destination image, expectancy, and satisfaction (Leal, 2004; Pérez-Nebra, 2005; Pérez-Nebra, Borges, \& Torres, n.d.; Rezende-Parker, Morrison, \& Ismail, 2003). Nowadays, consumer researchers already represent almost half of the professors of the marketing schools of the world (Simonson, Carmon, Dhar, Drolet, \& Nowlis, 2001), and studies concerning consumers can already be considered as the fastest growing area in anthropology and sociology (Miller, 1995).

Explanations with a social-cognitivist orientation have prevailed in the consumer field. In 1990, Foxall would already call attention to the popularity of this type of theoretical approach, highlighting its importance for scientific progress. In that context, the author proposed a model to analyze consumer behavior (i.e., Foxall, 1986, 1990), emphasizing the effects of consequence variables. Yet, what would be good predictors of consumer behavior? What impact do culture and cultural values 
have on consuming? It appears to be important to know the relationship between consumer behavior and cultural values in order to increase the prediction of consumer behavior choice.

Research has demonstrated (e.g., Allen, 2000; Richins, 1994) that the meaning of the product is one of the variables that predict searching and buying behavior. The meanings attributed to the service include two broad categories. The utilitarian meaning represents the tangible function of the service, which allows the individual to have some control over the environment (Dittmar, 1992). In this category, meaning is derived from the practical utility of the service and is intrinsically linked to its convenience, efficiency, and the exchange value per se. The utilitarian meaning relates mainly to the cognitive component of the attitute towards the product or service, which, as demonstrated by Cervellon and Dubé (2002), has a greater impact on the consumer intention and choice of members of individualist cultures.

The symbolic meaning is the result of social experiences, which lead to the subjective categorization of the service or product, via social institutions, communication systems, and the culture of a society. Attributes that are intangible and culturally shared are compilations of the image or symbolism of the chosen service. Thus, the symbolic meaning is strongly related to the culture of a group (Dittmar, 1992). Also, the symbolic meaning of the product is intrinsically related to the affective component of the product attitude, which appears to have a stronger influence on collectivists' consumer intention and choice, when compared to members of individualist cultures (Cervellon \& Dubé, 2002). However, as Kilbourne (1991) alerts, the term symbolic does not imply in lack of a functional meaning. Allen (2000) suggests that basic human values have a direct influence on consumer choice when individuals evaluate the symbolic meaning of a service, and therefore make an affective judgment about it. When consumers appraise the utilitarian meaning of a service, judging each of its utilitarian characteristics, values have an indirect influence on choice, through the service's tangible attributes.

Allen's model (Allen, 2000; Allen \& Ng, 1999a) has been tested with several products and services, such as holiday destinations, cars, eyeglasses, food, etc. (e.g., Allen \& Ng, 1999b) but only in individualistic cultures. Results obtained with the Two-Route Model confirm that the route by which values influence the choice of service is restricted by conditions, namely the utilitarian meaning of the service, and the accomplishment of a piecemeal judgment when the service has an instrumental function. When the service has an expressive function (i.e., symbolic meaning), consumers make an affective judgment concerning it, and human values transpose the analysis of the attributes of the tangible service and influence the preference directly. It is interesting to observe, however, that the instrumental function of the attitude towards a service plays a central role in the intention and choice to purchase such a service in individualist cultures (Cervellon \& Dubé, 2002). On the other hand, the expressive function of the attitude is central to members of collectivist cultures, who tend to understand the attitude object as a symbol or expression of their in-group, and thus, as a way to maintain in-group harmony. As Mooij (2004) argues, service attitudes in individualist cultures reflect ambivalence between affective and cognitive components. Because of their need to express private opinion, and make individual decisions, the cognitive component is more highly valued in this group. For collectivists, the affective and cognitive components are positively linked. Instead of opposing each other, people in collectivist cultures see the cognitive component as a mere integrating part of the affective component, which is broader in relevance. This is probably due to the fact that in collectivist cultures people are "we" conscious, placing a great deal of importance to harmony on in-group members and avoiding loss of face (Cervellon \& Dubé, 2002). This preference for instrumentality and utility in individualist cultures, when compared to the affective preference in collectivist cutlures (Aaker, 2006), might have implications for the Two-Route Model. Therefore, Allen's model needs to be tested in contexts where the self is interdependent (i.e., collectivist). Thus, the need to include the cultural variable in this study becomes apparent. It is proposed here that this variable can be captured by IC cultural patterns, which have been shown to be good predictors for behavior collections (Hofstede, 1980; Smith \& Bond, 1999), including Consumer behavior (Mooij, 2004). Nonetheless, no research has been found that directly investigated the relationship between cultural patterns and tourism consumer choice. 


\section{Tourism Destination Choice}

Studies (e.g., Klenoski, 2002) have presented some factors that influence destination choice behavior. These factors describe tangible and abstract attributes of the destinations (Gengler, Klenosky, \& Mulvey, 1993) that could be a proxy of the utilitarian and symbolic meaning. The attributes that attract travelers to particular destinations in different countries can be understood as follows.

In Nigeria, Awaritefe (2004) showed that motivations for tourist destination choices are: selfimprovement in an appreciative, educational or cultural context; leisure/recreational pursuits; attractiveness of destination; quality services; facilities/amenities; favourable location, and access to centres. Pérez-Nebra (2005) found similar dimensions to describe tourism destination images, such as local culture, luxury and comfort, scenery, security and infra-structure, and entertainment. Her study showed that only the scenery (e.g. tropical places) and entertainment (e.g. golf) dimensions had different perceptions between real and potential tourist. Therefore, these would be interesting categories to use in destination choice. Hall (2002) also emphasized that some cities had strong identities (e.g. Prague, Rio de Janeiro, Sidney), and could not be treated in the same way as a country destination (e.g. Scotland).

This study aims to identify and analyze some of the variables that have an impact on tourism destination choice. For that, besides capturing the holiday destination choice of Australians and Brazilians, their preferred judgment type (piecemeal vs. affective), product meaning (utilitarian vs. symbolic), and cultural values were also assessed. It should be noticed that individualistic cultures put the value in the person, whereas in collectivist cultures, identity is based in their in-group. Also, as Mooij (2004) suggests, members of collectivist cultures are likely to differ from members of individualist cultures in the way information is processed and interpreted. The individualistic independence from the group goes along a 'me' orientation, independent of the social context. Thus, for them, there is a concern for what the product or service does (i.e., its utility), that contrasts with the need of harmony and dependence of collectivists. For the latter, people buy or use products and services to avoid offending the social group, emphasizing the product or service symbolic meaning in accordance with the in-group values. Emotion, feelings, and other affective responses to stimuli, should be the preferred mode of operation to collectivist, while knowledge, beliefs, and other cognitive responses to stimuli are the favoured mode of operation of individualists.

Although there is substantial evidence for this difference based on culture (e.g., Cervellon \& Dubé, 2002; Shavitt et al., 2006), few research efforts have been conducted to test this difference in the preferred cultural mode of operation, that include collectivist cultures other than Asian, such as Brazil. This study was designed to respond to this need. Thus, based on the literature and arguments presented, this study tested the following three hypotheses.

Hypothesis 1: There is a difference between Australia and Brazil in the preferred cultural pattern. The main effect on cultural patterns between Brazil and Australia is such that Australians will score higher on individualism than collectivism, whereas Brazilian scores follow the opposite pattern.

Hypothesis 2: The independent self will prefer a piecemeal type of judgment and utilitarian meaning when compared to collectivists. Collectivists will use more affective judgment and symbolic/cultural meaning.

Hypothesis 3: The direct route between values and holiday destination choice will be stronger for the collectivist Brazilians than for the individualist Australians, since Brazilians will prefer affective judgment when deciding to which destination to travel, whereas Australians will prefer piecemeal judgment, using the indirect route. 


\section{METHOD}

\section{Participants}

University students and the population in general were included in the research due to the fact that these individuals are potential trevellers. College students were recruited in class in large universities in Australia and Brazil. Copies of the questionnaires were given to students, and the completed survey was returned in one week. When the completed surveys were returned to researchers, three additional copies were given to the students, who were asked to pass them on to participants from the general public. Using this procedure, of the 1,800 surveys sent out, 756 were satisfactorily returned, yielding an effective response rate of $42 \%$. Of those, 364 were responded by Australians, and the other 392 questionnaires were completed by the Brazilian sample. Data concerning demographic characteristics were gathered from each group of participants. Information on the participants' gender, age, and educational level is presented in Table 1.

Table 1: Gender, Age, and Educational Level of Participants

\begin{tabular}{llllllll}
\hline & \multicolumn{2}{c}{ Gender } & \multicolumn{2}{c}{ Age (years) } & \multicolumn{3}{c}{ Education } \\
\cline { 2 - 8 } & Male & Female & Mean & DP & High School & Undergraduate & Graduate \\
\hline Australians (n = 364) & $50.1 \%$ & $49.9 \%$ & 31 & 14.63 & 54,8 & 37,5 & 6,1 \\
Brazilians (n = 392) & $49.5 \%$ & $50.5 \%$ & 25 & 8.83 & 82,4 & 12,4 & 4,6 \\
\hline
\end{tabular}

The majority $(41,1 \%)$ of the Australian sample occupied clerical positions (i.e., administrative assistants, secretaries), and $36,7 \%$ of them claimed to be college students. When asked about their occupation, the majority of the Brazilian sample $(56,4 \%)$ also declared that they worked in clerical positions, and 27,9\% identified themselves as college students.

\section{Instruments}

A 6-page, self-administered questionnaire was given to participants. First, the questionnaire contained the Values Scale (32 items in the English version, and 45 items in the Portuguese version), the Meaning and Judgment Scale (19 items), and a Selection Criteria Questionnaire for Holiday Destination, a measure of places chosen for vacation in the past five years, and a small questionnaire on demographic data. Participants took, on average, 20 to 25 minutes to answer the entire survey. Because all the following instruments were originally created in English, the translation-retranslation technique (Brislin, 1980; Brislin, Lonner, \& Thorndike, 1973) was used to make sure the survey had language equivalence in Portuguese. Instruments are detailed as follows.

Values Measure. With the objective of measuring Brazilian cultural patterns, the Values Scale of Singelis et al. (1995) was employed. The original English version (administered to the Australian sample) of the scale contained 32 items and was designed to measure the individualist-collectivist vertical and horizontal values at the individual level. A version of the scale validated in Brazil has 44 items that individuals rate on a 1-9 'Strongly Disagree' to 'Strongly Agree' scale. To validate this version, focus groups made up of Brazilian college students were used to add items with content and language structure relevant to Brazilian culture. The version was then translated and back translated, and was first presented elsewhere (Torres \& Pérez-Nebra, 2005). As mentioned before, the instrument of Singelis et al. (1995) measures the constructs of vertical-horizontal individualism-collectivism, describing four types of cultural patterns, vertical individualism (VI), vertical collectivism (VC), 
horizontal individualism (HI) and horizontal collectivism (HC). In this study, the internal consistency coefficients for the four sub-scales of Singelis et al. (1995)'s instruments were calculated for both countries. These analyses resulted in reliability coefficients that were considered to be inadequate for the kind of assessment proposed in the study (for Brazilians, $\mathrm{VI}=.61$; $\mathrm{VC}=.61 ; \mathrm{HI}=.55$; and $\mathrm{HC}=$ .76 ; For Australians, $\mathrm{VI}=.46$; $\mathrm{VC}=.61$; $\mathrm{HI}=.49$; and $\mathrm{HC}=.70$.) Because the study proposed a difference in individualism-collectivism between the countries, only the scores of participants in individualism-collectivism were calculated. When only two sub-scales (individualism - collectivism) were calculated for both countries, the scores were considered to be more reliable (for Brazilians, $\alpha=$ .88 for collectivism, and $\alpha=.87$ for individualism; whereas for Australians, $\alpha=.88$ for collectivism and $\alpha=.91$ for individualism).

The Meaning and Judgment Scale (19 items) measures the preference for judgment type (piecemeal or affective) and the importance of product meaning (utilitarian or symbolic) (Allen, 1997; 2001).

Holiday Destination Measure. Using a scale ranging from 1 to 10 with 1 being "Not at all important" and 10 being "Very important", respondents rated the importance of attributes of holiday destinations. A pool of 25 attributes was then reduced with a factor analysis, and promax rotation $(\mathrm{KMO}=0.89)$, yielding 5 factors. The first factor refers to attributes of a Relaxing and Family destination (e.g., Safety; Relaxing Ambiance; alpha= 0.86). The other factors were Cultural destination (Museums, Galleries, Theatres; alpha= 0.82); Adventure destination (Stimulating; Exciting; Lots of Activities; alpha $=0.82$ ); Sophisticated destination (Sophisticated Restaurants; Shopping Facilities; alpha= 0.78); and Contact with Nature (Wild Place; Tropical; alpha= 0.77).

Consumption Behavior Measure. The survey ascked: "In the past 5 years, to which places have you been on vacation?" Participants were asked to write places where they had been and the number of times they had been there during this period. The places listed in the participants' answers were categorized into five groups by independent judges (graduate students) in both countries, who based their judgment on the tourism Destination Choice and Destination Image literature. Categories referred to Native places (e.g., Northern Territory in Australia, and the Amazon Rainforest in Brazil); Major Cities (e.g., Sydney and Rio de Janeiro); Prestige Places (e.g., Club Med); Scenery Places (e.g., Great Barrier Reef in Australia, and Northeastern Beaches in Brazil); and Overseas (e.g., Europe). The categories were transformed into dummy variables ( 0 or 1$)$, and multiplied by the number of times each participant reported visiting the place. This product was used as a dependent variable in later analyses. Participants took, on average, 25 minutes to answer the entire survey.

\section{RESULTS}

The first hypothesis refers to the cultural pattern preferred in each country. With a series of one-way ANOVAs, the main effects of cultural patterns between Brazil $(n=392)$ and Australia $(n=364)$ were tested and are reported in Table 2.

Table 2: Means, Standard Deviations, and One-Way ANOVAs of Cultural Pattern by Country

\begin{tabular}{|c|c|c|c|c|c|c|c|c|}
\hline \multirow[b]{2}{*}{ Cultural Pattern } & \multicolumn{3}{|c|}{ Brazil (N = 392) } & \multicolumn{5}{|c|}{ Australia $(\mathrm{N}=364)$} \\
\hline & $\mathrm{M}$ & SD & SE & $\mathrm{M}$ & SD & SE & $d f$ & $\mathrm{~F}$ \\
\hline Collectivism & 7.14 & 0.62 & 1.25 & 4.96 & 0.92 & 1.09 & 1,755 & $428.23^{* *}$ \\
\hline Individualism & 5.51 & 1.01 & 1.27 & 6.56 & 0.94 & 1.45 & 1,755 & $43.91^{* *}$ \\
\hline
\end{tabular}


The first hypothesis was accepted. As Table 2 demonstrates, there was an effect of country on cultural patterns. Brazilians had a higher score on collectivism than Australian respondents, while Australians had the opposite response pattern.

The second hypothesis suggested that people in individualist cultures (independent self) would prefer piecemeal judgment and utilitarian meaning, whereas people in collectivist cultures (interdependent self) use more affective judgment and symbolic/cultural meaning. To test this hypothesis, two ANOVAs were performed. The first one compared the mean ratings for affective and for piecemeal judgements between Australians and Brazilians. A significant interaction for Judgment Type and Country $\left(\mathrm{F}_{(1,720)}=13.21, \mathrm{p}<.001\right)$ was found. The second ANOVA compared the mean ratings for utilitarian and symbolic meanings between Australians and Brazilians, also yielding a significant interaction, although to a lower degree, for Meaning and Country of particiants ( $\mathrm{F}_{(1.720)}=$ 7.54, $\mathrm{p}<.01)$.

Hypothesis 2 was accepted. The results of the ANOVAs show that, essentially, Brazilian respondents prefer affective judgment type and symbolic meaning, when compared to Australians. There was also a significant interaction between the country of participants and the meaning attributed to the product.

To test Hypothesis 3, the product of category of places versus frequency was used as the dependent variable. An analysis of consumption behavior measure and of the choice of destination categorization revealed the following results. Most participants (59.8\% of Brazilians, and $36.3 \%$ of Australians) preferred going to Scenery Places. Some Australians (14.4\%) and Brazilians (11.9\%) spent their holidays in Major Cities in each country. A Native place was the holiday destination of $16.9 \%$ Brazilians and 12\% Australians, and more Australians (27.9\%) than Brazilians (5.5\%) declared that they went Overseas on their vacations. Few Australians (9.5\%) and Brazilians (5.8\%) chose a Prestige place for holidays.

Table 3 describes the correlations between each destination category, meaning and judgment preference, destination attributes, and horizontal-vertical individualism-collectivism values for both countries. Although not all correlations are significant, the meanings and judgments that form the basis of chosen destinations can be inferred, as well as the values related to it. As shown, all destination categories are negatively correlated with the piecemeal judgment and utilitarian meaning factor for Brazilians, and positively correlated for Australians. With affective judgment and symbolic meaning, the direction of the relationship is the opposite.

Table 3: Correlations between Holiday Destination, Meaning and Judgment Preference, Holiday Attributes, and Individualism, and Collectivism Horizontal-vertical Values

\begin{tabular}{|c|c|c|c|c|c|c|c|c|c|c|}
\hline & \multicolumn{5}{|c|}{ Brazilian Destination Categories } & \multicolumn{5}{|c|}{ Australian Destination Categories } \\
\hline & Nat & MC & Pre & Sce & Over & Nat & MC & Pre & Sce & Over \\
\hline \multicolumn{11}{|l|}{ Judgment \& Meaning } \\
\hline Piecemeal \& Utilitarian & $-.25 *$ & -.06 & $-.28 * *$ & $-.22 *$ & -.06 & .10 & .07 & $.22^{*}$ & $.22 *$ & .09 \\
\hline Affective \& Symbolic & $.23^{*}$ & .07 & $.29 * *$ & $.21^{*}$ & .10 & -.09 & -.05 & $-.21 *$ & $-.23 *$ & $-.21^{*}$ \\
\hline \multicolumn{11}{|l|}{ Attributes: } \\
\hline Cultural & -.09 & $.21 *$ & -.08 & .08 & .10 & $-.21 *$ & .10 & $-.21 *$ & .10 & .08 \\
\hline Relaxing & .08 & $.23 *$ & .09 & $.20^{*}$ & $.21^{*}$ & $.20^{*}$ & -.09 & $.21^{*}$ & $.22 *$ & $.20^{*}$ \\
\hline Adventure & -.10 & .08 & -.07 & .09 & -.10 & $.23 *$ & .08 & -.10 & .10 & $-.24 * *$ \\
\hline Sofisticated & -.07 & .09 & $.21^{*}$ & $-.22 *$ & $.22 *$ & -.09 & $.21^{*}$ & $.22^{*}$ & $.21^{*}$ & $.26 * *$ \\
\hline Contact Nature & .08 & -.09 & -.06 & $.24 * *$ & -.09 & $.28 * *$ & -.10 & -.10 & $.22^{*}$ & -.09 \\
\hline
\end{tabular}




\begin{tabular}{lllllllllll}
\hline VC & $.21^{*}$ & .10 & $.34^{* *}$ & $.25^{* *}$ & $.27^{* *}$ & -.10 & -.09 & $-.22^{*}$ & $-.21^{*}$ & $-.21^{*}$ \\
HC & .10 & .10 & $.28^{* *}$ & $.26^{* *}$ & $.26^{* *}$ & $-.21^{*}$ & -.08 & $-.21^{*}$ & -.09 & -.08 \\
VI & -.09 & -.09 & $-.21^{*}$ & $-.34^{* *}$ & $-.21^{*}$ & $.22^{*}$ & .07 & $.24^{* *}$ & $.22^{*}$ & .10 \\
HI & -.08 & -.05 & $-.26^{* *}$ & $-.22^{*}$ & $-.24^{* *}$ & $.23^{*}$ & .09 & $.22^{*}$ & .09 & $.21^{*}$ \\
\hline
\end{tabular}

Notes: Nat= Native Place; MC=Major Cities; Pre=Prestige; Sce= Scenery; Over=Overseas;

VC=Vertical Collectivism; HC=Horizontal Collectivism; VI=Vertical Individualism; HI=Horizontal Individualism;

${ }^{*} \mathrm{p}<0.05 * * \mathrm{p}<0.01$; Two-tailed significance, d.f. $=392$ and 362, respectively

In relation to cultural values, the collectivistic values correlated positively with the Brazilian destinations, negatively with the Australian destinations, and the opposite pattern was observed for individualistic values. Also, note that there are more significant correlations between values and destination categories for Brazilians than for Australians, indicating the greater importance of the value component in the choosing of a Brazilian's holiday destination choice. More destination attributes have a significant correlation with the Australian's holiday destination choices, which also suggests that the perceived attributes of the place play an important part in the holiday destination choice of Australians.

The third hypothesis was that the direct route between values and destination choice would be stronger for Brazilians than Australians. To test the proposition, both Brazilian and Australian destination categories were regressed onto the IC cultural values scores in a first regression set. Then hierarchical regressions were conducted, with Brazilian and Australian destinations being first regressed (Block 1) onto the five destination attributes subscales described above, and then on cultural values (Block 2). Most interesting are the R-squares from the regressions.

For the Brazilian-group regressions, cultural values alone did indeed predict the choice of a Scenery destination $\left(\mathrm{R}^{2}=.22, \mathrm{~F}_{(3,390)}=3.57, \mathrm{p}<.01\right)$. In the hierarchical regression, the destination attributes significantly predicted Scenery destination $\left(\mathrm{R}^{2}=.19, \mathrm{~F}_{(5,385)}=5.71, \mathrm{p}<.001\right)$, and cultural values in Block 2 added to this prediction $\left(\mathrm{R}^{2}\right.$ Change $=.20$, $\mathrm{F}$ Change $\left.{ }_{(8,387)}=3.52, \mathrm{p}<.05\right)$, indicating that the direct influence of values on Scenery destination choice is significant.

For Australians, no significant prediction was found between cultural values alone and Scenery Place destination. However, hierarchical regression results showed that destination attributes predict significantly this kind of destination $\left(\mathrm{R}^{2}=.24, \mathrm{~F}_{(5,360)}=4.92, \mathrm{p}<.001\right)$, with vertical/horizontal IC (Block 2) adding to this prediction $\left(\mathrm{R}^{2}\right.$ Change $=.15$, F Change $\left.(8,356)=3.52, \mathrm{p}<.01\right)$. The indirect influence of human values on Scenery Place destination choice is $0.09(0.24-0.15)$, the significance of which cannot be calculated. Therefore, for Brazilians, cultural values do indeed have a significant direct influence on the choice of a Scenery destination.

When Overseas destination choice was examined, it was found that, for Australians, cultural values alone did not describe a significant relationship, whereas for Brazilians, this relationship was obtained $\left(\mathrm{R}^{2}=.32, \mathrm{~F}_{(3,390)}=13.74, \mathrm{p}<.001\right)$. In the second set of regressions, attributes did predict Overseas destination for Australians $\left(\mathrm{R}^{2}=.29, \mathrm{~F}_{(5,305)}=23.20, \mathrm{p}<.001\right)$, with the contribution of cultural values (Block 2) for this prediction $\left(\mathrm{R}^{2}\right.$ Change $=.12$, $\mathrm{F}$ Change $\left.{ }_{(8,356)}=3.52, \mathrm{p}<.05\right)$. For Brazilians, destination attributes did predict Overseas choice $\left(\mathrm{R}^{2}=.21, \mathrm{~F}_{(5,358)}=17.68, \mathrm{p}<.05\right)$, with an increase in this prediction when cultural values enter in the hierarchical regression equation $\left(\mathrm{R}^{2}\right.$ Change $=.10$, F Change $\left._{(8,358)}=08.15, \mathrm{p}<.01\right)$.

In relation to Native Places, cultural values did predict the destination choice for Brazilians $\left(\mathrm{R}^{2}=\right.$ $\left..20, \mathrm{~F}_{(3,355)}=12.01, \mathrm{p}<.01\right)$. When destination attributes entered in the regression equation, $\mathrm{a}$ predition was also found $\left(\mathrm{R}^{2}=.17, \mathrm{~F}_{(5,355)}=15.33, \mathrm{p}<.05\right)$, with cultural values adding to this prediction $\left(\mathrm{R}^{2}\right.$ Change $=.13$, F Change $\left.{ }_{(8,355)}=14.40, \mathrm{p}<.05\right)$. In the Australian sample, only the destination attributes predicted the Native Place choice in the hierarchical regression $\left(R^{2}=.16, F_{(5,305)}\right.$ 
$=09.37, \mathrm{p}<.05)$. The results for cultural values did not show any significance in the linear, or in the hierarchical regressions (Block 2).

The results for a Prestige place destination showed that, for Brazilians, cultural values did predict the destination $\left(\mathrm{R}^{2}=.26, \mathrm{~F}_{(3,361)}=17.45, \mathrm{p}<.001\right)$. In the hierarchical regression, destination attributes also predicted Prestige destination $\left(\mathrm{R}^{2}=.17, \mathrm{~F}_{(5,361)}=14.61, \mathrm{p}<.05\right)$, with cultural values adding to this prediction $\left(\mathrm{R}^{2}\right.$ Change $=.13$, F Change $\left.{ }_{(8,361)}=33.80, \mathrm{p}<.01\right)$. For Australians, the cultural values scores had no significance for Prestige place prediction. For this sample's hierarchical regression, it was observed that destination attributes (Block 1) predicted Prestige destination $\left(\mathrm{R}^{2}=.21, \mathrm{~F}(5,305)=\right.$ 03.53, $\mathrm{p}<.05$ ), with cultural values (Block 2$)$ adding to this prediction $\left(\mathrm{R}^{2}\right.$ Change $=.11$, $\mathrm{F}$ Change ${ }_{(8}$, 356) $=02.25, \mathrm{p}<.05$ ). These results indicate that for Australians, destination acts as a mediator in the relationship between cultural values and Prestige destination choice, suggesting that the indirect route is the preferred one for this group.

It was interesting to notice that for Major Cities destination, no relationship was found for Australians or Brazilians, neither in the linear regressions (i.e., cultural values alone as predictors), nor in the hierarchical regressions (i.e., attributes - Block 1; and cultural values - Block 2). These results suggest that, for this specific destination, other variables not measured in this study might explain this choice.

Taken together, the results show that although cultural values influence most Brazilians' choice of holiday destination by influencing destination attributes, which in turn influence the destination choice itself (i.e., indirect route), the analyses of the R-squares show that the direct route between values and destination choice is stronger for Brazilians than for Australians. Australians, on the other hand, prefer the indirect route when chosing their holidays destinations.

Finally, it should be noted that all the regressions described in this section were recalculated to control for demographic data (gender, age, and education). In those regressions, demographic characteristics were entered in a first block, then destination attributes (Block 2), followed by values (Block 3). The results of these regressions paralleled the original regressions, demonstrating that demographics do not account for the findings.

\section{DISCUSSION}

Hypothesis 1 predicted a relationship between preferred cultural patterns and country of residence. The Brazilian sample had a predominantly collectivist cultural pattern and the Australian participants tended to prefer individualism (Smith \& Bond, 1999). Australia is considered to be an individualist culture (Hofstede, 1980).

Hypothesis 2 was also accepted. It was suggested that Australians would prefer piecemeal judgment and utilitarian meaning, while Brazilians would prefer affective judgment and symbolic meaning. Indeed, there was an effect of country on judgment type and meaning, so much so that the preference for affective judgment was especially true for Brazilians when compared to Australians. These results support the difference found between individualists and collectivists in the importance attributed to cognitive and affective components of attitude (Cervellon \& Dubé, 2002). Piecemeal judgment reflects a calculative and rational consideration of each attribute of the object of the attitude, in this case, the holiday destination choice. This type of judgment corresponds to the information processing described by the Expectancy Theory (Fishbein, 1967), which fits the evaluation process of individualists, where even affective responses are judged cognitively (e.g., “I wonder, why do I feel relaxed?”). Affective judgment is holistic and gestaltic in nature, judging the object as a whole, which is not considered the Expectancy Theory. Indeed, this type of judgment reflects the evaluation of the value symbolized by the object as a whole, which appears to be the preferred type of jugdment made by collectivists. Therefore, these data provide evidence for the role of affect in information processing of collectivists (e.g., “I don’t know why I bought this. I just liked it!”). As discussed elsewhere (e.g., Mooij, 2004; 
Shavitt et al., 2006), the cognition-affect interaction varies across cultures and product categories. What our data have shown is that a consumer's culture or cultural orientation also influences the nature of service judgment and meaning.

These data should be carefully considered when designing campaigns or ads that target the Brazilian or Australian population. As indicated here, marketing strategies that stress the collectivistic values endorsed by Brazilians, positioning the service (in this case, holiday destinations) in line with these values, might have a greater appeal for these individuals.

Hypothesis 3 was accepted. As mentioned above, Allen's Two-Route Model suggests that there are two ways human values may influence product preference. Results shown here suggest that consumers who hold collectivist values may be using the direct route of influence on holiday destination choice more than those who endorse individualist values. Individualists consumers form their attitudes toward destinations by evaluating human values symbolized by the destination against human values that they endorse. As suggested by Allen, Ng and Wilson (2000), the item which symbolizes a human value that an individual endorses, results in a more positive attitude toward that item. On the other hand, items that symbolize a human value that the individual rejects, result in an unfavorable attitude.

Examining the regression results in the Brazilian sample, it was observed that human values, more specifically collectivism, add to the explanation of holiday destination choice. This result shows that human values form one basis of holiday destination choice, in addition to the objective attributes of the destination. When considering human values, the present study investigates one aspect of subjective culture. For Triandis (1994), the analysis of subjective culture leads to the understanding of how people shape their perception, and transfer value to their environment. Therefore, the present study provides evidence for the ethic validity of Allen's two-route model in collectivist cultures. In other words, the two routes by which human values influence product preference must appear to be of universal equivalence.

Moreover, what has been demonstrated by this finding is that the relationship between human values and holiday destination choice is present in collectivist Brazilian culture. We can assume that choice between routes for destination preference and the symbolism attached to the destination is universal. However, more samples from different countries must be included in order to provide a strong basis for this argument.

For future studies we also suggest the inclusion of the variable country self-destination image. The majority of destination choices made by tourists was in the same country. This self-image might be affecting the choice and the evaluation (Pérez-Nebra, 2005).

Lastly, it is important to observe that although our results showed that the Two-Route Model is valid for Brazilian culture, more studies should be done to investigate the validity of the Model in other collectivist cultures. Besides Asian cultures, often used to draw collectivist samples, other cultures should be investigated to assess the universal validity of the Model. For instance, the 22 countries in Latin America have cultural differences among themselves, but all of them can be considered collectivists. Additionally, each country has sub-cultures or groups that are different from one another. Because groups within a society can be differentiated in terms of a large number of criteria, the choice of groups which should be studied can be a difficult one. Therefore, more samples must be investigated in order to provide a better understanding of the pattern of holiday destination choice in different cultures.

\section{REFERENCES}

Aaker, J. L. (2006). Delineating culture. Journal of Consumer Psychology, 16(4), 343-347. 
Allen, M. W. (1997). The direct and indirect influences of human values on consumer choices. Unpublished doctoral dissertation, Victoria University of Wellington, New Zealand.

Allen, M. W. (2000). The attribute-mediation and product meaning approaches to the influences of human values on consumer choices. In F. C. Huntington (Eds). Advances in Psychology Research (Vol. 1, pp. 1-76). NY: Nova Science Publishers.

Allen, M. W. (2001). A practical method for uncovering the direct and indirect relationships between human values and consumer purchases. Journal of Consumer Marketing, 18(2) 102-120.

Allen, M. W., \& Ng, S. H. (1999a). The direct and indirect influences of human values on product ownership. Journal of Economic Psychology, 20(1), 5-39.

Allen, M. W., \& Ng, S. H. (1999b). The psychology of poverty. In P. E. Earl \& S. Kemp (Eds). The elgar companion to consumer research and economic psychology (pp. 463-468). Cheltenham, UK: Elgar.

Allen, M. W., Ng, S. H., \& Wilson, M. (2000). A functional approach to instrumental and terminal values and the value-attitude-behavior system of consumer choice. European Journal of Marketing, 36(1-2), 111-138.

Allen, M. W., Ng, S. H., \& Wilson, M. (2002). The functional approach to instrumental and terminal values and the value-attitude-behavior system. European Journal of Marketing, 36(1/2), 111135.

Ashmos, D. P., \& McDaniel, R. R. (1996). Understanding the participation of critical task specialists in strategic decision making. Decision Sciences, 27(1), 103-113.

Awaritefe, O. D. (2004). Motivation and other considerations in tourist destination. Tourism Geographies, 6(3), 303-330.

Brislin, R. W. (1980). Translation and content analysis of oral and written materials. In H. C. Triandis \& J. W. Berry (Orgs.). Handbook of cross-cultural psychology (Vol. 4, pp. 398-444). Boston: Allyn \& Bacon.

Brislin, R. W., Lonner, W., \& Throndike, R. M. (1973). Cross-cultural research methods. New York: Wiley.

Campbell, D. J., Bommer, W., \& Yeo, E. (1993). Perceptions of appropriate leadership style: participation versus consultation across two cultures. Asia Pacific Journal of Management, 10(1), 1-19.

Cervellon, M. C., \& Dubé, L. (2002). Assessing the cross-cultural applicability of affective and cognitive components of attitude. Journal of Cross-Cultural Psychology, 33(3), 346-357.

Mooij, M. K. de (2004). Consumer behavior and culture: consequences for global marketing and advertising. London: Sage.

Dittmar, H. (1992). The social psychology of material possessions: to have is to be. New York: St. Martin's.

Ferdman, B. M. (1992). The dynamics of ethnic diversity in organizations: toward integrative models. In K. Kelly (Ed). Issues, theory and research in industrial/organizational psychology (pp. 339-384). Amsterdam: North Holland.

Fishbein, M. (1967). A behavior theory approach to the relations between beliefs about an object and the attitude toward the object. In M. Fishbein (Ed.). Readings in attitude theory and measurement (pp. 389-400). New York: John Wiley \& Sons. 
Foxall, G. R. (1986). Consumer choice in behavioral perspective. European Journal of Marketing, 20(3), 7-18.

Foxall, G. R. (1990). Consumer psychology in behavioral perspective. New York: Routledge.

Gengler, C. E., Klenosky, D. B., \& Mulvey, M. S. (1993). Understanding the factors influencing ski destination choice: a means-end analytic approach. Journal of Leisure Research, 25(4), 36279.

Hall, D. (2002). Brand development, tourism and national identity: re-imaging of former Yugoslavia. Journal of Brand Management, 9(4/5), 323-34.

Heller, M. (1987). The role of language in the formation of ethnic identity. In J. S. Phinney \& M. J. Rotheram (Eds). Children's ethnic socialization: pluralism and development. Newbury Park, CA: Sage.

Hofstede, G. (1980). Culture’s consequences. Beverly Hills, CA: Sage.

Hofstede, G. (1983). The cultural relativity of organizational practices and theories. International Business Studies, 14(2), 75-89

Hofstede, G. (1991). Cultures and Organizations. London: McGraw-Hill.

Kahle, L. R. (1996). Social values and consumer behavior: research from the list of values. In C. Seligman, J. M. Olson, \& M. Zanna (Eds.). The psychology of values: the ontario symposium (pp. 135-151). NJ: Lawrence Erlbaum Associates.

Kilbourne, W. E. (1991). The impact of the symbolic dimensions of possession on individual potential: a phenomenological perspective. Journal of Social Behavior and Personality, 6(6), 445-56.

Klenoski, D. B. (2002). The "pull” of tourism destinations: a means-end investigation. Journal of Travel Research, 40(4), 385-95.

Leal, S. (2004). A imagem de destinações turísticas: um estudo de caso do Brasil na percepção de alunos baseados na Austrália. Retur, 2(2), 1-8

Miller, D. (1995). Consumption and commodities. Annual Review of Anthropology, 24, 141-161.

Nogueira, A. H. A. (2001). Padrões culturais e normas para comportamentos de liderança: um estudo comparativo entre empregados de empresas de previência privada do Brasil e dos EUA. Unpublished Master's degree dissertation, University of Brasilia, Brasilia, Brasil.

Nogueira, A. H. A., Torres, C. V., Guimarães, T. A., \& Lucas, E. C. (2002). Cultural patterns and styles of leadership: a comparative study among Brazilian and American employees. Biannual Conference of the International Society for the Study of Work and Organizational Values. Varsóvia, Poland, 8.

Pearson, V. M., \& Stephan, W. G. (1998). Preferences for styles of negotiation: a comparison of Brasil and the U.S. International Journal of Intercultural Relations, 22(1), 67-83.

Pérez-Nebra, A. R. (2005). Medindo a imagem do destino turístico. Master's thesis, University of Brasilia, DF, Brazil.

Pérez-Nebra, A. R.; Borges, C. P.; \& Torres, C. V. (n.d.). What do you think of Brazil as a destination? A scale and a method for measuring consumer satisfaction and expectancy of Brazil [Working paper]. Psychology Institute, University of Brasília, Brazil. 
Rezende-Parker, A. M., Morrison, A. M., \& Ismail, J. A. (2003). Dazed and confused? An exploratory study of the image of Brazil as a travel destination. Journal of Vacation Marketing, 9(3), 243-259.

Richins, M. L. (1994). Valuing things: the public and private meanings of possessions. Journal of Consumer Research, 21(3), 19-26.

Shavitt, S., Lalwani, A. K., Zhang, J., \& Torelli, C. J. (2006). The horizontal/vertical distinction in cross-cultural consumer research. Journal of Consumer Psychology, 16(4), 325-356.

Simonson, I., Carmon, Z., Dhar, R., Drolet, A., \& Nowlis, S. M. (2001). Consumer research: in search of identity. Annual Review of Psychology, 52, 249-275.

Singelis, T. M., Triandis, H. C., Bhawuk, D. P. S., \& Gelfand, M. J. (1995). Horizontal and vertical dimensions of individualism and collectivism: a theoretical and measurement refinement. Cross-Cultural Research, 29(3), 240-75.

Smith, P. B., \& Bond, M. H. (1999). Social psychology: across cultures (2nd ed.). Boston: Allyn \& Bacon.

Smith, P. B., Bond, M. H., \& Kagitçibasi, C. (2006). Understanding social psychology across cultures: living and working in a changing world. London: Sage.

Sönmez, S., \& Sirakaya E. (2002). A distorted destination image? The case of Tourkey. Journal of Travel Research, 41(2), 185-196

Torres, C. V. (1999). Leadership style norms among americans and brazilians: assessing differences using jackson's return potential model. Doctoral dissertation, California School of Professional Psychology, CSPP, USA.

Torres, C. V., \& Dessen, M. A. (2002). Family and socialization factors in Brazil: an overview. In W. J. Lonner, D. L. Dinnel, S. A. Haynes, \& D. N. Sattler (Eds). Online readings in psychology and culture (Vol. 13, pp. 1-11). Washington, D.C.: Western Washington University, Center for Cross-Cultural Research.

Torres, C. V., \& Pérez-Nebra, A. R. (2005). Assessing vertical and horizontal manifestations of individualism and collectivism in Brazil: revising a values scale. Anais do Congresso Interamericano de Psicologia, Buenos Aires, Argentina, 30.

Triandis, H. C. (1994). Cross-cultural industrial and organizational psychology. In H. C. Triandis, M. D. Dunnette, \& L. M. Hough (Eds). Handbook of industrial and organizational psychology (2nd Ed., Vol. 4.). Palo Alto, CA: Consulting Psychologists Press.

Triandis, H. C., \& Gelfand, M. J. (1998). Converging measurement of horizontal and vertical individualism and collectivism. Journal of Personality and Social Psychology, 74(1), 118-128.

Triandis, H. C., Chen, X. P., \& Chan, D. K. (1998). Scenarios for the measurement of individualism and collectivism. Journal of Cross-Cultural Psychology, 29, 275-289.

Triandis, H. C., McCusker, C., \& Hui, C. H. (1990). Multimethod probes of individualism and collectivism. Journal of Personality and Social Psychology, 59(5), 1006-1020.

Van Horn, K. R., \& Marques, J. C. (1999). Development of interpersonal negotiation strategies in Brazilian adolescents. Interamerican Journal of Psychology, 32(1), 21-31. 